\title{
Alternate Method for the Failure of Antitheft Device used in Motor Vehicles
}

\author{
I.V.N.S Aditya ${ }^{1}$, Y. Radha Krishna Murthy² \\ and Lt. Ravindra Babu Kallam³ \\ ${ }^{1}$ Computer Science \& Engineering, Aizza College of Engineering \& Technology. Mulkalla. \\ ${ }^{2}$ Assistant Professor, Computer Science \& Engineering. Aizza College of Engineering \& Technology.Mulkalla. \\ ${ }^{3}$ Research Scholar (JTNUH) \& HOD, Computer Science \& Engineering, Aizza College of Engineering \& \\ Technology. Mulkalla, India.
}

\begin{abstract}
The Biometrics can be used in the security mechanism for the motor vehicles, as an anti theft device. In this we focus on the existing systems like, antitheft device using eye retina scanner, thumb scanner, their merits and demerits.

To overcome limitations in the existing system we have proposed a new method.

The two devices, retinal scanner and thumb scanner can be used as one alternate to another. If one method is failed, the user can be authenticated by using another method. The failure of the device or failure of particular component in the device can be indicated to the user by using LEDs.
\end{abstract}

\section{General Terms}

Security, Interface, Compare, Matching.

\section{Keywords}

Eye retina scanner, EEPROM, LED, relay, keypad, and switch.

\section{INTRODUCTION}

Motor vehicles are the general transport system that the people are using now. The most important challenge for the owners of the motor vehicles is providing security to their vehicles. The entire world is facing a problem with motor vehicle theft. To over come this several people had given their suggestions and proposed new antitheft systems in motor vehicles.

Among them Adam Wlofsen from Denver proposed an antitheft device for motor vehicles. Mr. Adam Wolfsen used the technique of eye retina matching of the user for providing the security to the motor vehicles. The schematic illustration of Wolfsen system is as shown in Figure 1. [1]

Figure 1. Wolfsen's Schematic illustration [1] [2]

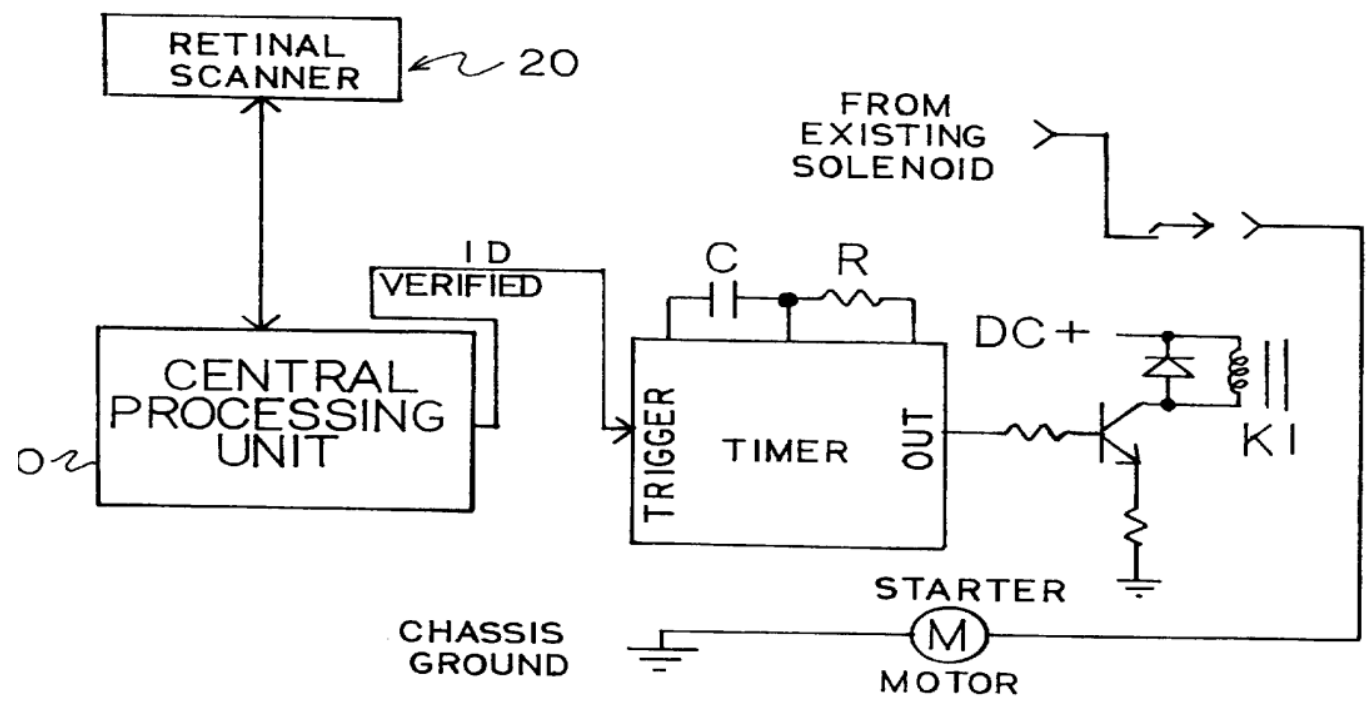


Stephen J. Borza from Ottawa, Canada proposed an antitheft device for motor vehicles. He used the technique of finger print matching biometric system for user authentication. The block diagram of Mr. Stephen is as shown in Figure 2. [4]

The main disadvantage in above two existing systems is, the systems never discussed about the hardware failures. The solenoid and the starter motor will never closed electrically when the circuit is failed because of any reason. The vehicle will not be started until the entire system is replaced or repaired.

The hardware failure may occur because of thermal, voltage fluctuations or any other problems. The device will never give at lest an indication to the user that the system got failed.
In the world there are so many inventions to protect the vehicles from the unauthorized users and the thiefs, but that should not create problem for the authorized users or the owners of the vehicles.

In such a case forget about the thief, the genuine user cannot even start the vehicle. It is most hectic problem facing by the users world wide.

To solve the above problem we have proposed a new method to combine two biometric systems as a anti theft device, so if one does not work the owner can ignite the vehicle by using an alternate method.

Figure 2. Stephen's Block Diagram

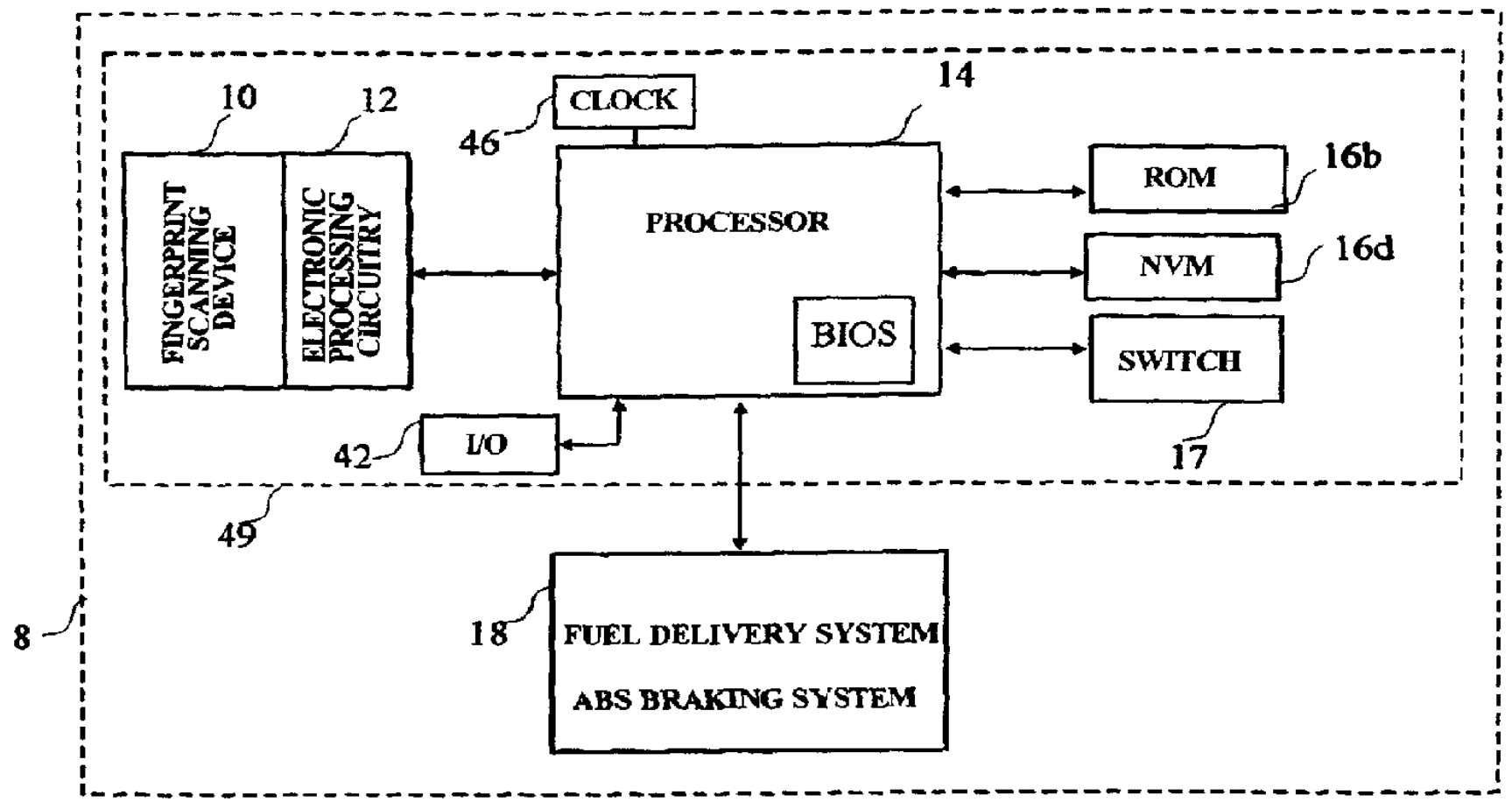

\section{PROPOSED SYSTEM}

To eradicate the above mentioned problem we have proposed a new antitheft device for motor vehicles. We have used the combination of eye retina scanner and thumb scanner as a device to provide security. We have provided an alternative method to ignite the vehicle even if, one of the methods is failed. The proposed device itself indicates its failure and enable the user by glowing the LEDs.

\subsection{Design}

The design of our proposal is similar to existing systems. In addition to the existing circuit we are providing two electronic components prior to the each hardware component present in the circuit. The two components Relay switch and LED are placed before to the components hence they acts as checkpoint to the component. The Relay switch consists of two contacts one is Normally Open and another is Normally Close. We are connecting the normally closed contact to the component such as central processing unit, timer function and etc. The normally opened contact is connected to a LED; this contact will work only when the component at the normally closed circuit is failed. That means the LED will be glow only when the component nearer to it is failed. [6]

In addition to the above design we are also providing a circuit that is used to provide authentication to the user by thumb impression scanning and matching with the existing patterns. The design will be similar to above retina scanning system. [5]

The outputs of the two circuits are connected to their respective normally closed contacts of relay switches. An 'OR' gate will be placed between the two circuits with the outputs of two circuits as an input. We will connect input of the 'OR' gate from the relay normally closed contact. The normally open contacts of relays are connected to LEDs as shown in Figure 3. [7] 
Figure 3. Proposed Schematic Illustration

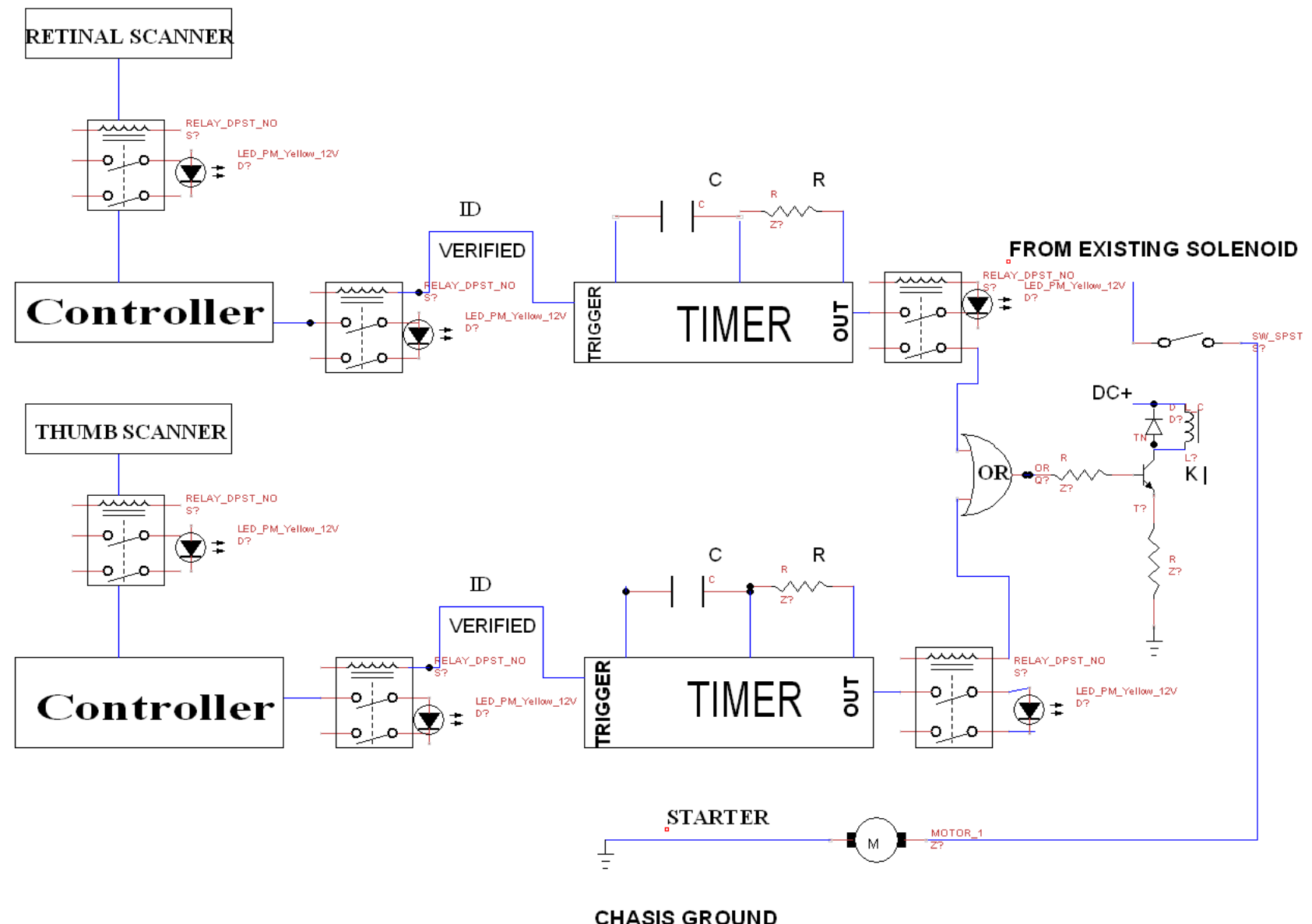

CHASIS GROUND

\subsection{Work Flow}

In our proposal the user can be allowed to use the car in 3 modes of operation.

Normal Condition, when the vehicle's ignition is given, the eye retina scanner and thumb scanners will be started and scans the eye retina and thumb impression of the driver individually. The scanned patterns are sent to the central processing unit through the relay switch. If the central processing unit is working properly the regular functioning will be done. If the central processing unit is not working properly the LED will be glow. The same scenario can be conducted before the timer circuit and the coil. If the failure is occurred at any component then the LED prior to the component will glow. As the outputs are connected to an 'OR' gate, the car will be started only if the eye retina or thumb are matched with the already stored patterns. If the scanned patterns are not matched with the existing patterns then the car will not be started. [3] [4]

If eye retina scanning circuit is failed, the user can realize the failure of circuit by observing the LEDs in the circuit. The alternate circuit thumb scanner works. If the user is authenticated then the vehicle will be started normally.
If thumb scanner is failed, the user can realize the failure of circuit by observing the LEDs in the circuit. The alternate circuit retina scanner works. If the user is authenticated then the vehicle will be started normally.

\section{FEATURES}

- We can provide high level authentication to the user.

- The vehicle will work properly even if one of the circuits is failed.

- The user can easily find the failure of the circuit using LEDs.

\section{LIMITATIONS}

- In the design we are using the Relay switches, the coil of the switch may be failed.

- In case of two circuits are failed, the motor vehicle will never be started.

\section{CONCLUSION}

In this we have explained about our new method for developing anti theft device, which is a combination of eye ryes and thumb 
impression devices with OR gate. Initially we have discussed about the existing anti theft devices, it merits and de merits.

Finally, we have given an alternative approach on the failure of the antitheft device, by which the authorized user can ignite the vehicle. The failure of the device can also indicate by the LEDs provided in the Circuit, it helps us to easily repair the devices.

We like to conclude that, it is an user friendly anti theft device, can be used by automobile industries.

\section{ACKNOWLEDGMENTS}

We would like to thank our beloved parents for their overwhelming support all along.

The first author would like to thank his beloved parents $\mathrm{Mr}$. I.V.S Sai Prasad and Mrs. Jyothirmangathayi for their valuable support and encouragement.

We also thank the management of Aizza College of Engineering \& Technology for allowing us to work on this in the college campus.

\section{REFERENCES}

[1] Adam Wolfsen, "Retina Scanning Anti-Theft Device For Motor Vehicles", U.S Patent Document Number: $5,845,733$.

[2] Ronald Weiss, "Combination Breathalyzer and eye-sensor" U.S Patent Document Number: 6,433,863.

[3] Sudha Guptha , "Iris Recongnition system using Biometric Template Matching Technology", International Journal of Computer Application

[4] Stephen J. Borza, "Biometrically secured control system for preventing the Unauthorized use of a vehicle". U.S Patent Document Number: 5,867,802.

[5] V.S Meenakshi,"Retina and Eyeris Based Multimodel Biometric Fuzzy vault". IJCA Ref Id: pxc387669 